\title{
The application of ethnographic method in the research of social work in enterprise

\author{
Du Shi
}

\author{
Department of Sociology in Changchun University of Science and Technology \\ Changchun city ,Jilin, Peoples R China
}

\begin{abstract}
Keywords: Social Work in Enterprise, Social Research Methods, Qualitative Research, Ethnographic method.
\end{abstract}

\begin{abstract}
In research of social work in enterprise, the method of ethnography makes researchers understand the enterprise effectively, A combination of methods like documentation, interview and participant observation should be employed. This method can also be applied to the preliminary investigation of the enterprise organization, and becomes a set of operational research methods. This method emphasizes research of enterprise at a micro level and the bottom-up research path; At the same time, it helps researchers be aware of problems that exist in the enterprise and help the enterprise to improve its current situation. this method it can also strengthen the humanistic care for employees, and pay attention to the actual situation of the multidimensional dimensions of the staff's life and psychology.
\end{abstract}

\section{论民族志方法在企业社会工作调研中的应用}

\author{
杜 实 \\ 长春理工大学法学院社会学系, 吉林, 长春, 中国
}

关键词：企业社会工作、社会调查方法、质性研究、民族志方法

中文摘要: 在企业社会工作研究与实践中, 民族志方法能让研究者更有效地认识和进入企业, 将文献、访谈和参与观察等质性方法融为一体, 有机运用到关于企业组织的前期调研中, 成 为一套可操作的调研方法。这种方法的实施是强调微观层面的企业调研, 突出自下而上的研 究路径; 同时, 有助于我们确立问题意识, 助力企业改善现状; 还能够加强企业的人文情怀, 关注员工的生活和心理等多元维度的实际状况。

\section{1. 引言}

作为运用社会工作方法解决员工问题的新兴专业领域, 我国目前的企业社会工作研究主 要存在以下两种倾向, 一是从学科方向发展和理论建构的宏观角度展开研究, 突出西学本土 化的思路; 二是从企业社会工作的实务模式进行探讨，突出这一专业的实践应用策略。当然， 不论在何种倾向下，认识和了解作为概念抑或实体的 “企业” 就成为研究得以顺利进行的基 础, 这就谈到了如何对企业进行调研的问题。这样一来, 企业社会工作就要与社会调查方法 的思路相结合, 进行方法论层面的思考, 成为基础研究的一个方面。同时, 从现实服务角度 来看, 这也是一个具体操作问题, 是开展社会工作服务前的必要准备。

在企业社会工作研究中，民族志方法能让研究者更有效地认识和进入企业，这套方法的 
理念和实践可追溯到人类学、社会学早期对企业相关问题展开的调研。在方法的定位上, 它 属于社会调查方法中的质性研究或定性研究范围, 并可以与田野作业方法画约等号, 最初是 人类学学者对他者 “异文化” 的微观调研和文本书写, 是一套以科学田野作业为主要内容的 调查方法, 记录某一有组织且持续存在的团体独特的生活方式。如今, 除了对特定族群的社 会文化进行勾勒外, 不少学者开始将民族志方法拓展到现代的组织环境中, 逐渐催生了企业 民族志、工业民族志、市场民族志等新型调查和书写文本, 强调对个案特点的挖掘与解读, 并进一步拓展出相应的类型化描述。而企业社会工作在本质上也存在民族志方法强调的个案 特殊性倾向，如不同国家和地区企业社会工作的经验、不同行业和企业的社会工作实务取向 等等, 这些模式得以形成必须以细致的调研作为其前提一一擅于将文献、访谈和参与观察等 技巧融为一体民族志方法由此成为一套可操作的调研手段。

\section{2. 西方学者的企业民族志经验}

关于民族志方法用于国外企业调研的经验, 人类学家沃纳在 20 世纪 30 年代加入企业管 理领域著名的霍桑试验, 倡导在组织研究中使用民族志方法, 并发现企业中非正式组织和政 事组织同时存在, 而前者有其特殊规范, 对人们的行为起到调节和控制作用, 如已经适应已 有奖惩制度的工人会在私下形成的小团体内达成默契，使产量只保持在中等以上，以至于所 有人都不会因产量不达标而被惩罚。从整体来看, 霍桑试验继续保持并延续了人类学者在乡 土社会研究的特点, 将企业看做一个小社会, 运用功能论和均衡论对企业中管理者和工人之 间的横向关系、纵向关系以及工人之间的冲突进行了详细记录和分析, 并考察了工人士气与 管理理念的关系。在研究方法上, 霍桑试验从一个最初的受控试验, 转为一个访谈研究, 并 发展成为一个定性的田野调查。从这个意义上来说, 霍桑实验是极力倡导在组织研究中使用 民族志和定性研究方法, 并且从中获益的成功案例。

随后, 越来越多的学者加入对企业进行民族志调研的阵营中: 一方面, 对企业内部的生 产、管理环节进行研究, 如怀特对 “餐饮业”、管道公司和集装箱公司的研究, 理查德森和 沃尔克对 IBM 公司 Endicott 工厂的研究等; 另一方面, 学者还将研究拓展至企业外部的员工 社区展开调研, 切入到与企业相关联的员工生活层面, 挖掘工厂与其所属社区的相依关系和 相互影响, 如基辛等人研究了加州某工业企业移民安置情况及其与下辖社区之间的关系。到 了 20 世纪七八十年代, 社会学和人类学史中的著名学者也展开了有关企业的相关研究: 迈克 尔 - 布洛维在赞比亚的一个机械工厂回答了为什么工人如此努力地超额完成任务的问题 (1)。保罗 - 威利斯于对英国工人子弟从技术学校到上岗工作的转变历程 ${ }^{2}$ 很感兴趣, 认为英国 工人阶级子弟在学校中总是茂视规则, 喜欢说脏话和打架, 这其中的原因往往出自他们的家 庭习惯。其父辈以迟到、早退或消极急工的方式进行的无意识反抗已经被悄然复制到工人子 弟身上。人类学家拉比诺于对美国掌握 PCR（复制某一特定 DNA 片段）技术的西特斯公司 进行考察, 积累大量第一手资料, 全面系统地描述这一技术的发明史 ${ }^{3}$, 讨论了生物技术产业 发展背后的技术、文化、社会、经济等诸多要素。

\section{3. 中国学者的企业民族志经验}

通过对国内学者的企业民族志研究进行梳理, 我们能够大致将其分为两种研究取向, 一 是对工厂、企业等行业组织进行社会文化意义的调查与分析。如 1927 到 1930 年, 陶孟和先 后对塘沽工人、北平工人、华北铁路工人和华北纺织工人进行社会调查, 内容涉及到工人的 工资、消费、休闲、娱乐、福利设施等各个方面。1940 年, 史国衡对某军需工厂的工人生活 状况进行调查, 涉及到农民向工人身份转变过程中带来的工作和生活方式上的变化, 这也是 乡村文化与都市文化相互协调的社会事实 ${ }^{(4)}$ 。21 世纪以来, 美国华裔学者流心将研究矛头直 指中国市场经济浪潮对人们道德与人性的冲击, 对广西某高科技类上市公司进行田野调查, 
通过捕捉处长、老板、“小姐”三类人的讲述，揭示了中国市场经济转型下 “自我” 结构中 的 “他性” (5一社会剧烈变革中的中国人可能在金钱的鬼惑下迷失自己, 出现人格的异化。 陈石在博士学位论文中对深圳某物业投资集团下属的五星级酒店进行田野调查, 将其置于中 国经济社会转型的背景中进行分析, 认为在市场经济转型的过程中企业的产权变革是一把双 刃剑，带来机遇的同时也带来挑战。

二是将工厂工人作为阶级整体进行社会再生产意义的讨论。21 世纪初，吴清军、李亚雄 和李晓非运用政治学的阶级理论, 分别从社会学、政治学和民族学的角度对中国 C 市的拖拉 机厂 ${ }^{\circ}$ 、武汉江厂和中州 Z 厂 进行调研, 以丰富的经验材料分析了国企工人在市场转型中的变 迁过程。吴清军提出底层社会 “阶级再形成” 的观点, 为研究当前社会结构中的工人群体提 供了一种解释的可能性, 他认为市场转型时期的下岗失业工人形成了一个 “底层社会” 阶级, 这是因体制转轨而出现的阶段性现象, 并不具有代际传承性, 这种阶级势必随着单位制、身 份制的解体以及国家法律制度与劳动力市场的不断完善而逐渐走向灭亡。李亚雄主要把国营 工厂看作是国家的一部分，把国家、国有企业和国企职工看作是相对独立的能动主体，着力 于揭示三者之间的互动以及由互动形成的关系，试图分析国营工厂的制度结构及运作，认为 国有企业的制度变迁经历了从政企合一到分离的过程。从江厂的情况，作者看到改革以来国 有企业与国家之间的关系正在从行政隶属关系向产权关系转变。李晓非则通过对国有企业 $\mathrm{Z}$ 厂及其职工群体的田野调查, 结合学术前辈对该厂丰硕的前期研究成果, 整理出 $Z$ 厂在存续 50 余年间的工厂变迁民族志，进而引入一个社会学和人类学的分析概念—— “家园”，用以 解析围绕以 $\mathrm{Z}$ 厂为家的工人群体在国企改制前后所发生一系列故事背后的根本动力和原因。

\section{4. 从企业民族志到企业社会工作调研}

当然，企业民族志并不等同于企业社会工作的前期调研，后者还需要从自身实际需要和 实务发展的角度进一步提出具体思路。一般认为, 企业社会工作是在 20 世纪 70 年代以 “解 决员工问题” 的专业角度被正式提出, 其具体形式是美国 “员工协助方案（EAP）” 的开展。 如果从民族志撰写的视角来看, 这种解决问题的方案正是基于对企业及其职工的现实情况和 存在问题的调研所得, 进而有针对性地展开社会工作实务。由此, 美国的企业社会工作者得 以进入工作场所, 最大限度地发挥专业的力量。根据调研的实际结果, EAP 起初为雇员及其 家庭提供情感婚姻、行为医疗等问题的咨询。经过不断发展, 它所涵盖的服务内容日渐增多, 开始渗透到残障员工、物质滥用、工作场所的安全和健康、离职等问题的服务。

另外，企业社会工作的前期调研还包括对就业适应问题进行的个案管理，如 20 世纪 90 年代, 美国的福利政策发生重大转变, 即要求以往能够直接获得政府福利补助的贫困人群, 到一些入职标准较低的岗位工作, 可以说那时很多的传统福利接受者（多为单亲家庭的育龄 妇女）都被迫进入劳动力市场，在精神上有巨大的焦虑和压力，工作难以维持。于是，企业 社会工作者面向这类就业人群, 通过民族志式的微观调查来获取丰富的一手材料, 包括访谈、 参与式观察、追踪回访等基本手段, 对员工个案进行管理。这种从福利到就业的转型, 实际 上对企业社会工作者提出了更高的要求。

中国的企业社会工作则始于 21 世纪初期，学者们通过对不同企业实际情况的摸索与总 结, 提炼出多种具有代表性的实务运作模式, 如厂内运作模式、企业购买模式、工业园区模 式、项目嵌入模式的大体分类。而这些分类的提出正是来源于对企业及其员工现实问题的调 研和搜集，即民族志方法的应用及拓展。同时，根据服务需求方或企业社会工作前期调研与 需求评估发起者的角度, 我们也可以做出以下区分:

厂内运作模式和企业购买模式构成了第一种区分的可能，即企业本身作为调研与需求的 主体。管理者根据企业的实际运作情况和员工表现出来的工作状态, 调配组织内部或外部的 资源一一或将社会工作者招聘到企业内部开展专职服务, 或对外出资购买社会工作机构的专 门服务——并在企业内成立社会工作部门（具体名称可称为 “员工活动中心” 等），让专业 
的企业社会工作者入驻企业, 通过个案和小组工作方法对企业员工进行辅导服务, 以减少劳 资冲突和员工的心理紧张的状态, 促使企业员工形成良好的工作关系和职业适应能力。这样 不仅使企业福利项目不断完善, 也促使企业社会工作者提供人性关怀的专业服务, 将企业和 职工的思维和行动统一起来。

另一种可能则由工业园区模式和项目嵌入模式共同构成，即由企业以外的主体发起企业 社会工作调研与服务的需求。这一模式的发动主体可谓多方互动一一由政府相关部门、提供 服务的社会工作机构和接受服务的企业达成多方协议, 设立企业社会工作办事中心, 入驻企 业（或其所在的工业园区）。企业社会工作者运用社会工作理论与方法，为员工提供情感关 怀、个案救助、文化学习、娱乐活动、心理和法律咨询、紧急援助等多元服务, 致力于探索 企业社会工作的创新性实践。

\section{5. 结语}

由此可见, 中西方的社会学和人类学学科中一直含有对企业进行民族志调研的学科传统, 都在相关理论学派和具体问题的共同作用下, 出产经典论著。而一旦将这种方法用于企业社 会工作前期调研的借鉴当中, 我们还需要根据学科特点做进一步调试, 并应该着重突出以下 特点。

第一, 将民族志方法引入企业社会工作的研究和实践, 其实质就是强调微观层面的调研, 突出自下而上的特写观照。民族志调研强调对企业展开体察入微的考察, 这就使企业社会工 作的视角面向所有员工, 从最本真和基础的需要出发, 一方面对内总结出紧扣企业实际的实 务策划, 另一方面对外为不同企业社工模式的运作提供现实的经验支撑, 从而更加科学、合 理的凝聚出多种服务手段。

第二，我们也能够看到，传统意义的民族志文本除进行社会面貌的调查以外，还试图揭 示隐藏在社会表象背后的社会结构, 这实际上是要确立研究对象的独特性, 并明确具体的问 题意识。而一旦将调研目标聚焦于企业面临的具体问题, 我们就可以建构出一种助力企业改 善现状的民族志写作方法, 有助于对企业员工在职业发展、团队建设和福利保障等方面遇到 的问题进行跟踪，根据企业实际情况展开企业社会工作服务。

第三, 不论如何, 企业社会工作的调研和实务最终都是要落实到企业及其员工的正向改 变上。一旦将民族志的方法引入该领域, 企业社会工作者就要扩充认知维度, 进一步关注员 工的居住状况、日常生活和心理动态, 从人文关怀的角度帮助员工缓解自身压力、减轻内心 焦虑、提高工作热情。通过民族志调研, 调查者可以更充分地认识到企业和员工的现状与需 求，让二者的利益得以结合，产生共赢效果，最终增强企业的凝聚力。

综上所述, 民族志方法为企业社会工作前期调查的开展提供了重要的借鉴和参考, 而企 业社会工作领域的一个个生动案例也为民族志方法本身提供了具体和丰富的研究资料。因此, 推进两者的交流与融合应当被上升为企业社会工作基础方法论建构的高度, 通过不断的研究 和实践，使这种方法得到不断应用。

\section{References}

[1] Michael Buraway, Manufacturing consent: Changes in the labor Process under Monopoly Capitalism, The University of Chicago Press, pp. 89, 1979.

[2] Paul Willis, Learning to Labor: How Working Class Kids Get Working Class jobs, Ash gate Publishing, pp.18, 1977.

[3] Paul Rabinow, Making PCR: A Story of Biotechnology, The University of Chicago Press, 1996.

[4] ZHANG Ji-jiao, An Overview of Enterprise Anthropology: A Frontier Discipline Worldwide, Journal of Hangzhou Normal University Humanities and Social Sciences, Vol.4, 2014. 
[5] Xin Liu, The Otherness of Self: A Genealogy of The Self in Contemporary China, The University of Michigan Press, pp.2, 2002.

[6] Qingjun Wu, Reform of State-Owned Enterprises and Transition of old Industrial Workers, Social Sciences Academic Press(China), 2010. 